\title{
Toxicidade do pericarpo da Jatropha curcas em ovinos
}

\author{
[Jatropha curcas pericarp toxicity in sheep] \\ O.R. Ferreira ${ }^{1}$, S.S. Brito ${ }^{1}$, F.G. Lima ${ }^{4}$, D.P. Mariano Souza ${ }^{1}$, S. Mendonça ${ }^{2}$, J.A.A. Ribeiro ${ }^{2}$, \\ P.C. Maiorka ${ }^{3}$, V.L. Araújo ${ }^{1}$, J.N.M. Neiva ${ }^{1}$, M.C.S. Fioravante ${ }^{4}$, \\ A.T. Ramos ${ }^{1}$, V.M. Maruo ${ }^{1 *}$ \\ ${ }^{1}$ Escola de Medicina Veterinária e Zootecnia - Universidade Federal do Tocantins - Campus de Araguaína, TO \\ ${ }^{2}$ Embrapa Agroenergia - Brasília, DF \\ ${ }^{3}$ Faculdade de Medicina Veterinária e Zootecnia - Universidade de São Paulo, SP \\ ${ }^{4}$ Escola de Veterinária - Universidade Federal de Goiás, GO
}

\begin{abstract}
RESUMO
O pinhão manso (Jatropha curcas) é uma planta cultivada para a produção de biocombustível. O pericarpo é um coproduto com potencial para alimentação animal, e a presença de componentes tóxicos, principalmente ésteres de forbol, pode limitar sua utilização. Assim, objetivou-se avaliar a toxicidade do pericarpo. Vinte ovinos foram distribuídos em quatro grupos - um grupo-controle, que não recebeu a planta, e três experimentais, que receberam o pericarpo nas concentrações de $15 \%$ (G15), 30\% (G30) e $45 \%$ (G45), durante 23 dias. Após o $10^{\circ}$ dia, a ingestão do pericarpo promoveu redução do consumo de alimento, diarreia, desidratação e caquexia. Todos os grupos tratados apresentaram redução na concentração de fosfatase alcalina. Animais do G30 apresentaram redução na concentração de ureia e proteínas totais e elevação de potássio e sódio. No G45, houve aumento de aspartato aminotransferase, albumina, creatinina bilirrubina indireta e total. A avaliação anatomo-histopatológica revelou ascite, hidropericárdio, congestão no trato gastrintestinal e nos pulmões, edema pulmonar, aderências à parede torácica, degeneração hepática centrolobular e das células tubulares renais, pneumonia linfo-histiocitica e enterite linfoplasmocitária e histiocítica. À análise fitoquímica, constatou-se $0,3845 \mathrm{mg}$ de ésteres de forbol/g de pericarpo. Conclui-se que o pericarpo de J. curcas é tóxico, não sendo recomendado para alimentação de ovinos.
\end{abstract}

Palavras-chave: pinhão-manso, planta tóxica, coproduto, biocombustível

\begin{abstract}
Physic nut (Jatropha curcas) is a plant cultivated for biofuel production. Pericarp is a potential livestock food source by-product. However, its use may be limited due to the presence of toxic compounds, mainly phorbol esters. Thus, this study aimed to evaluate pericarp toxicity. Twenty sheep were divided in four groups, one control group which did not receive the plant and three experimental groups which received pericarp in 15\% (G15), 30\% (G30) and 45\% (G45) concentrations for 23 days. After 10 days of treatment, pericarp ingestion produced food intake decrease, diarrhea, dehydration and loss of body condition. All treated groups showed decrease in alkaline phosphatase activity. G30 animals presented reductions in urea and total protein concentrations, and increase in potassium and sodium levels. G45 animals showed increase in serum aspartate aminotransferase activity and in albumin, creatinin, total and indirect bilirubin levels. Anatomohistopathologic findings included ascites, hydropericardium, congestion of the gastintestinal tract and lungs, pulmonary edema and adhesions in the thoracic cavity, renal tubular cells and centrilobular cytoplasmic vacuolation and lymphohistiocytic pneumonia and lymphoplasmacytic and histiocytic enteritis. On the physiochemical analysis $0.3845 \mathrm{mg}$ of phorbol esters $/ g$ of pericarp were detected. It is concluded that J. curcas pericarp is toxic and is not recommended for sheep feeding.
\end{abstract}

Keywords: physic nut, toxic plant, byproducts, biofuel

Recebido em 13 de novembro de 2011

Aceito em 12 de janeiro de 2012

*Autor para correspondência (corresponding author)

E-mail: vivimaruo@uft.edu.br 


\section{Ferreira et al.}

\section{INTRODUÇÃO}

A Jatropha curcas, conhecida popularmente como pinhão manso, é uma planta pertencente à família Euphorbiaceae, que possui sementes ricas em óleo e vem sendo utilizada para produção de biodiesel em países das Américas Central e do Sul, África e Ásia (Becker e Makkar, 2008; Parawira, 2010). Os biocombustíveis têm atraído atenção por serem fontes de energia renováveis e biodegradáveis, constituindo uma alternativa para a substituição dos combustíveis fósseis, que estão associados a desequilíbrios ambientais, como a chuva ácida e o aquecimento global (Makkar e Becker, 2009).

As sementes de $J$. curcas contêm de $30-40 \%$ de óleo e, quando cultivadas em condições adequadas, apresentam maior rendimento de óleo por hectare que outras culturas, tais como: girassol, soja, milho e algodão (Makkar e Becker, 2009). Durante o processamento das sementes, são gerados como coprodutos a torta e o pericarpo do fruto, ambos com possibilidade de utilização na alimentação animal devido ao seu alto potencial nutritivo (Kumar e Sharma, 2008; King et al., 2009).

Sabe-se que as sementes de J. curcas contêm fatores antinutricionais, como inibidores de tripsina, taninos, saponinas, fitatos e lectinas, e compostos tóxicos, como a curcina e os ésteres de forbol, o que limita seu uso como fonte de alimento (Makkar et al., 1998). Entretanto, há relatos da presença de variedades de J. curcas não tóxicas no México. Estudo com as sementes dessa planta em diversas localidades demonstrou que a concentração de fitatos, inibidores de tripsina e da curcina, foi semelhante em todas as variedades, e que a concentração de ésteres de forbol foi significativamente menor nas variedades não tóxicas provenientes do México. Dessa forma, a toxicidade das sementes de $J$. curcas deve-se à presença dos ésteres de forbol (Makkar et al., 1997).

Os ésteres de forbol são moléculas derivadas de diterpenos tetracíclicos, restritos às famílias Euphorbiaceae e Thymelaceae, que ativam a proteína quinase $\mathrm{C}(\mathrm{PKC})$ de forma semelhante ao diacilglicerol, contudo a força de interação entre a enzima e os ésteres de forbol é mais forte, provocando sua hiperativação (Goel et al., 2007; Griner e Kazanietz, 2007). A PKC é formada por uma família de quinases que regula vários processos celulares, incluindo proliferação, apoptose, sobrevivência e migração celular, existindo ainda evidência substancial ligando a PKC à gênese de tumores (Griner e Kazanietz, 2007). Adicionalmente, os ésteres de forbol apresentam atividade inflamatória pela ativação da enzima fosfolipase $\mathrm{A}$, que hidrolisa os fosfolipídeos de membrana, resultando na produção de ácido araquidônico, secreção de prostaglandinas e leucotrienos e migração celular transendotelial (Goel et al., 2007).

A toxicidade de extratos obtidos da semente, óleo, raiz, látex, casca, fruto e folha da J. curcas para microrganismos e animais superiores está bem estabelecida. De forma geral, esses extratos possuem atividades moluscicida, ictiocida, inseticida, rodenticida, antimicrobiana $\mathrm{e}$ citotóxica e exercem efeitos adversos em animais, incluindo ratos, aves domésticas e ruminantes (Devappa et al., 2010). Embora existam trabalhos acerca da toxicidade das sementes e outros coprodutos, pouco se sabe sobre a toxicidade do pericarpo da J. curcas. O crescente uso da planta para a produção de biodiesel aumentará a frequência de contato de seus coprodutos com humanos, animais e outros organismos, tornando importantes os estudos de sua toxicidade visando estabelecer medidas de controle para evitar intoxicações (Devappa et al., 2010). Dessa forma, no presente trabalho, objetivou-se avaliar a toxicidade de três diferentes porcentagens de inclusão do pericarpo da $J$. curcas, cultivada na Amazônia Oriental, na alimentação de ovinos.

\section{MATERIAL E MÉTODOS}

O pericarpo de J. curcas utilizado neste estudo foi obtido da Biotins, agroindústria localizada na cidade de Paraíso-TO. Para o isolamento do princípio tóxico, o pericarpo foi moído em moinho estacionário (Willye TE-650) e congelado. As amostras foram encaminhadas à Central de Análises Químicas e Instrumentais do Centro Nacional de Pesquisa em Agroenergia (Embrapa Agroenergia - Brasília-DF), para detecção e quantificação dos ésteres de forbol.

A quantificação dos ésteres de forbol se iniciou com a extração desse composto segundo método descrito por Ribeiro et al. (2010). Neste método, $3,0 \mathrm{~g}$ da amostra foram transferidos para celas do extrator acelerado de gorduras ASE 350 (Dionex Corporation $\left.{ }^{\circledR}\right)$ e extraídos a $60^{\circ} \mathrm{C}$ com metanol. 
O extrato foi concentrado sob corrente de nitrogênio em bloco de aquecimento a $60^{\circ} \mathrm{C}$. O resíduo oleoso foi ressuspendido com metanol, centrifugado, e o sobrenadante límpido foi diluído quantitativamente para $5 \mathrm{~mL}$ com o mesmo solvente.

O extrato metanólico obtido foi filtrado e injetado em um sistema de cromatografia líquida de alta eficiência ProStar (Varian Inc.()), utilizando-se coluna Zorbax SB-C18 $(250 \times 4,6 \mathrm{~mm}, \quad 5 \mu \mathrm{m}, \quad$ Agilent Technologies $®)$ mantida a $40^{\circ} \mathrm{C}$, gradiente de eluição de ácido fosfórico $0,1 \%$ e acetonitrila a $1,1 \mathrm{~mL} / \mathrm{min}$ e detecção ultravioleta a $280 \mathrm{~nm}$. Como padrão externo para a quantificação, utilizou-se o Phorbol 12-myristate 13-acetate (SigmaAldrich $\left.{ }^{\circledR}\right)$.

Vinte ovinos machos, com média de idade de seis meses, foram distribuídos em quatro grupos e mantidos individualmente em gaiolas metabólicas, onde receberam água e alimentação ad libitum. Os ovinos foram alimentados durante 23 dias com feno de Panicum maximum cv. Mombaça adicionado de 15\% (G15), 30\% (G30) e $45 \%$ (G45) do pericarpo de J. curcas, ambos triturados. O grupo-controle recebeu apenas feno. A alimentação foi fornecida duas vezes ao dia, e os animais foram avaliados durante todo o período experimental, quanto ao consumo de alimento e ao aparecimento de sinais de toxicidade.

Ao final do experimento, os animais foram examinados, e amostras de sangue foram colhidas por punção da jugular para a realização de hemograma completo e obtenção de soro para análise do perfil bioquímico. A seguir, os animais foram eutanasiados e necropsiados. Fragmentos do SNC, hipófise, pulmões, fígado, baço, rins, adrenal, abomaso, intestinos e linfonodo mesentérico foram coletados e fixados em formol tamponado a $10 \%$ e processados rotineiramente para inclusão em parafina, cortados a $3 \mu \mathrm{m}$ e corados com hematoxilina e eosina.

Os resultados obtidos foram submetidos à ANOVA e ao teste Dunnett para comparação entre os grupos experimentais e o controle, considerando-se a significância de 5\%. As análises foram efetuadas utilizando-se o software GraphPad Prism v 3.00 para Windows 95® (GraphPad Prism, 1999).

\section{RESULTADOS E DISCUSSÃO}

Os ésteres de forbol são citados como sendo os principais componentes tóxicos da J. curcas, e, de fato, a análise fitoquímica confirmou a presença de ésteres de forbol na concentração de 0,3845mg de éster de forbol/g de pericarpo. O pico de eluição do padrão externo utilizado apresentou tempo de retenção de $23,71 \mathrm{~min}$, e os ésteres de forbol da amostra eluíram na região entre 17,00 e 21,50min (Fig. 1). A concentração de éster de forbol no pericarpo de J. curcas encontrada nesse estudo é menor que as observadas por Makkar et al. (1997), que analisaram os ésteres de forbol nas sementes de 18 variedades de diferentes origens e obtiveram concentrações de 0,87 a $3,32 \mathrm{mg} / \mathrm{g}$. Tal fato é decorrente, possivelmente, da característica lipofílica das moléculas desse composto, o qual se concentra em partes da planta ricas em óleo, como é o caso das sementes (Devappa et al., 2010).

A inclusão do pericarpo de $J$. curcas na dieta de ovinos provocou redução no consumo de alimento (Fig. 2) e no ganho de peso (Fig. 3). De fato, os animais usualmente limitam o consumo de plantas que contêm toxinas, por meio de mecanismos de retroalimentação afetivos e cognitivos relacionados diretamente ao sabor ou aos seus efeitos pós-ingestivos. Assim, alimentos de sabor desagradável ou que promovem sensações desagradáveis após seu consumo têm sua ingestão reduzida (Provenza et al., 1992). Dessa forma, a redução dose-dependente no consumo de alimento observada neste estudo pode ser atribuída à associação de vários compostos presentes na planta. As saponinas, que possuem sabor amargo, podem ser responsáveis pela redução na palatabilidade (Sen et al., 1998); os taninos, por exercerem efeitos antinutricionais, pela formação de complexos com proteínas do alimento, redução na digestibilidade de nutrientes e inibição do crescimento e atividade da microflora ruminal (Goel et al., 2005; Jayanegaraa e Palupi, 2010); e as lectinas, que se ligam a células epiteliais da mucosa do estômago e intestinos, podem induzir mudanças em processos digestivos, absortivos, protetivos ou secretórios de todo trato digestório e afetar a proliferação e o turnover celular (Vasconcelos e Oliveira, 2004). 


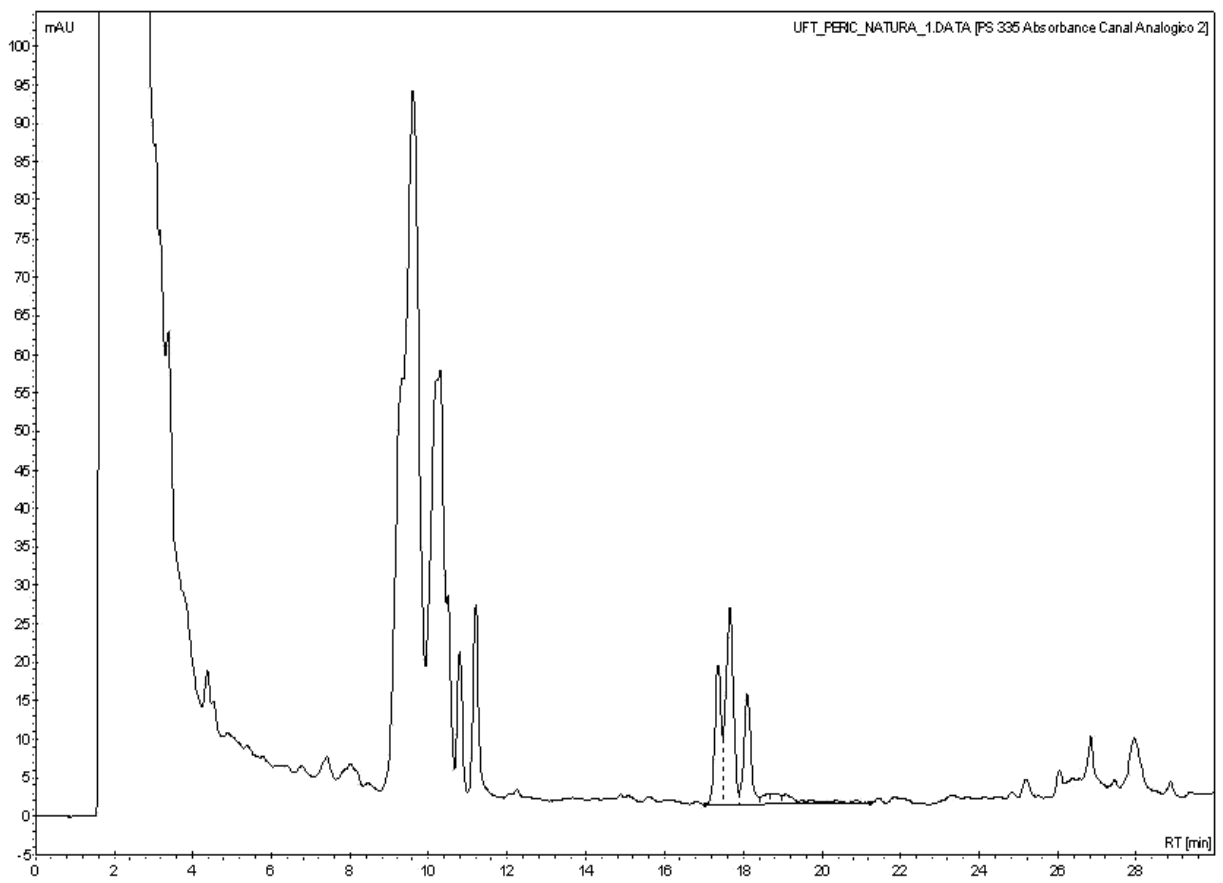

Figura 1. Cromatograma do extrato metanólico obtido do pericarpo de Jatropha curcas.

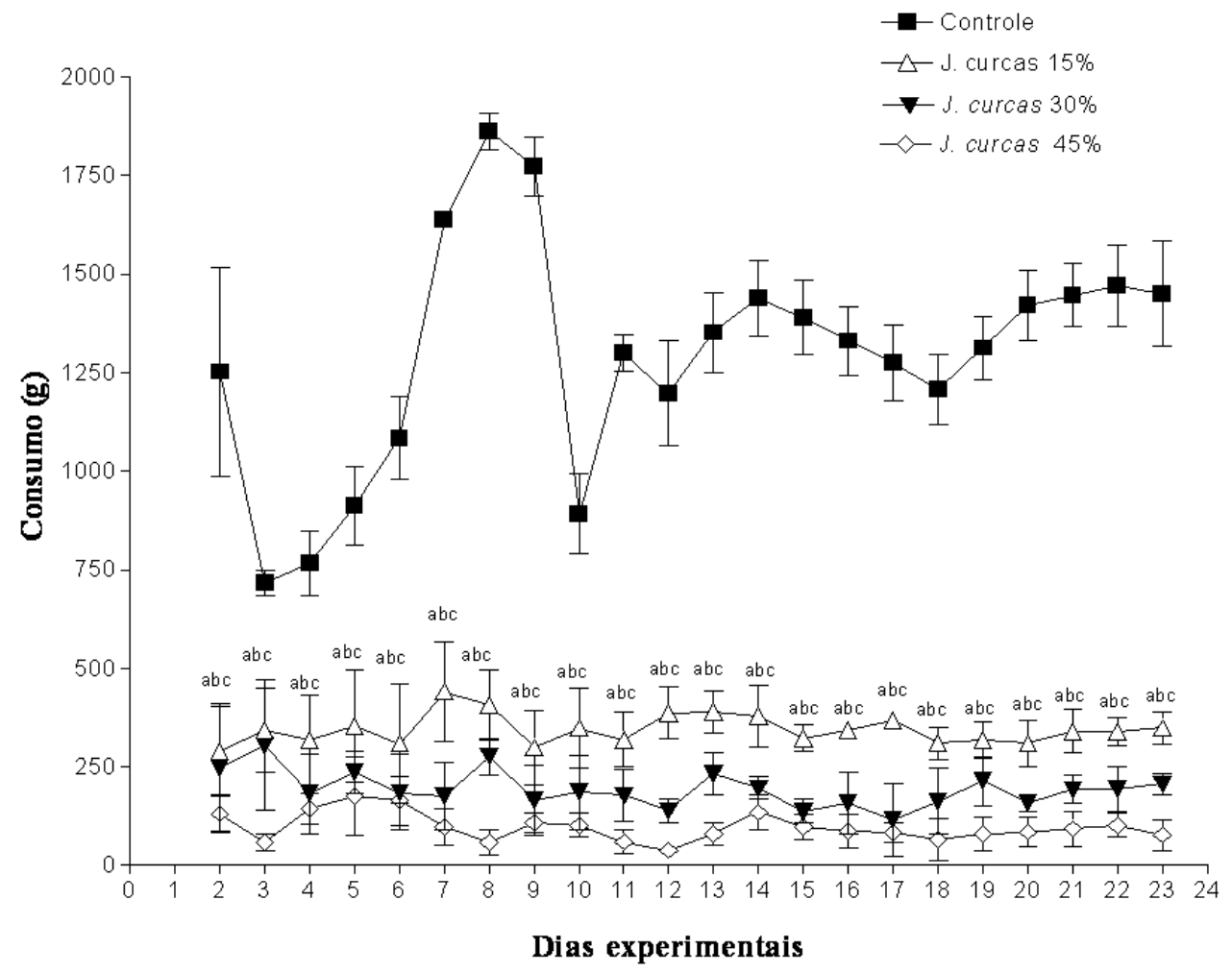

Figura 2. Consumo diário de alimento, em gramas, por ovinos controle e tratados durante 23 dias com $15 \%, 30 \%$ e $45 \%$ do pericarpo de Jatropha curcas incluída na alimentação.

${ }^{\mathrm{abc}}$ Diferem $(P<0,05)$ do tratamento controle, pelo teste Dunnett. 


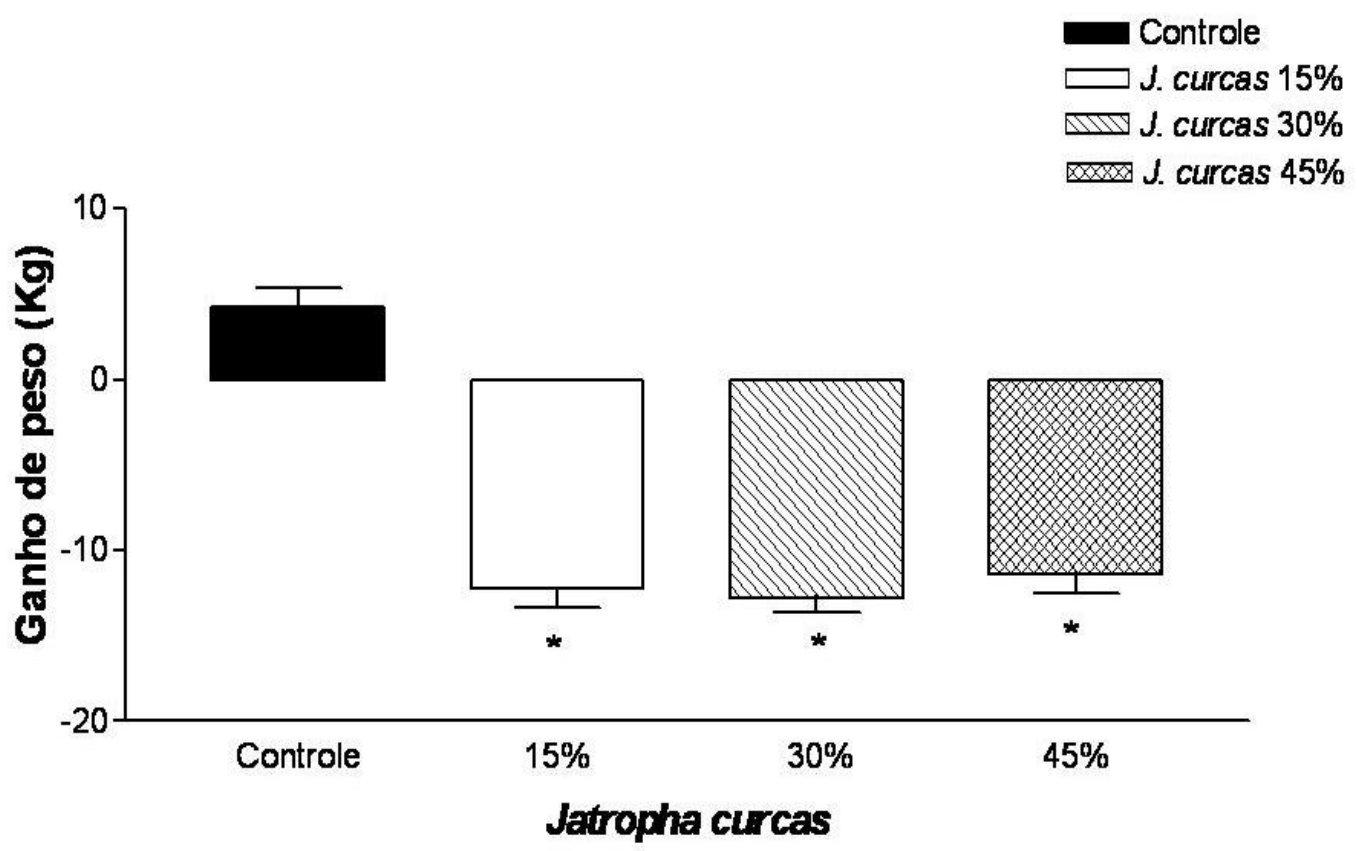

Figura 3. Ganho de peso (kg), de ovinos-controle e ovinos tratados durante 23 dias com $15 \%$, $30 \%$ e $45 \%$ do pericarpo de Jatropha curcas, incluída na alimentação.

*Difere $(P<0,05)$ do tratamento-controle pelo teste Dunnett.

Todos os animais alimentados com o pericarpo apresentaram intoxicação, caracterizada por caquexia, diarreia, mucosas hipocoradas, desidratação, alopecia, bradipneia, respiração crepitante e tosse, a partir do $10^{\circ}$ dia de tratamento. Adicionalmente, um animal do G30 apresentou diarreia profusa, escura e fétida, rinorreia, dispneia grave, decúbito e morte no $15^{\circ}$ dia de tratamento, sendo necropsiado em seguida. De fato, os animais do G30 ingeriram as maiores doses de ésteres de forbol. Ao final dos experimentos, além das alterações já descritas, houve diferença no aspecto das fezes dos animais: no G15 as fezes possuíam características mais próximas do normal, no G30 encontravam-se mais secas e no G45 apresentavam-se com volume diminuído, ressequidas e amareladas, refletindo a severidade da desidratação e o comprometimento do sistema digestório.

As variáveis hematológicas não foram afetadas pelo consumo da planta (dados não apresentados). Contudo, nas variáveis bioquímicas (Tab. 1), foi verificada redução de fosfatase alcalina em todos os grupos experimentais. Adicionalmente, no G30 houve elevação de sódio e potássio e redução nas concentrações séricas de proteínas totais e ureia, e no G45 elevação nas concentrações de aspartato aminotransferase (AST), albumina, creatinina e bilirrubina indireta e total. Essas alterações indicam nefro e hepatotoxicidade.

Durante a avaliação anatomopatológica, foram observados, em todos os animais, ascite, hidrotórax e hidropericárdio caracterizado por transudato modificado, edema pulmonar caracterizado por grande quantidade de espuma na traqueia, congestão no abomaso, intestinos, mesentério e pulmões, sufusões na serosa do rúmen e retículo aderências entre os pulmões e a parede torácica e aumento dos linfonodos mesentéricos. Adicionalmente, no animal que morreu foi observada enterite hemorrágica. À histopatologia, foram observadas alterações inflamatórias e circulatórias na mucosa intestinal e nos pulmões e alterações degenerativas hepáticas e renais (Tab. 2 e Fig. 4). Os demais órgãos não apresentaram alterações. 


\section{Ferreira et al.}

Tabela 1. Média e erro-padrão da média dos valores séricos de fosfatase alcalina (U/L), aspartato aminotransferase $(\mathrm{U} / \mathrm{L})$, alanina aminotransferase $(\mathrm{U} / \mathrm{L})$, albumina $(\mathrm{g} / \mathrm{L})$, proteína total $(\mathrm{U} / \mathrm{L})$, globulina $(\mathrm{U} / \mathrm{L})$, ureia $(\mu \mathrm{mol} / \mathrm{L})$, creatinina $(\mathrm{g} / \mathrm{L})$, sódio $(\mathrm{g} / \mathrm{L})$, potássio $(\mathrm{g} / \mathrm{L})$, bilirrubina direta $(\mu \mathrm{mol} / \mathrm{L})$, bilirrubina indireta $(\mu \mathrm{mol} / \mathrm{L})$ e bilirrubina total $(\mu \mathrm{mol} / \mathrm{L})$ de ovinos controle e ovinos alimentados durante 23 dias com dieta com diferentes porcentagens de pericarpo de J. curcas

\begin{tabular}{lcccc}
\hline Parâmetros & Controle & G15 & G30 & G45 \\
\hline FA & $277,00 \pm 24,37$ & $57,75 \pm 3,37^{*}$ & $84,50 \pm 9,47^{*}$ & $104,20 \pm 14,46^{*}$ \\
AST & $197,12 \pm 15,45$ & $296,76 \pm 48,65$ & $193,82 \pm 31,97$ & $384,24 \pm 31,51^{*}$ \\
ALT & $34,43 \pm 2,70$ & $28,18 \pm 3,34$ & $22,75 \pm 1,17$ & $38,56 \pm 5,93$ \\
Colesterol & $48,62 \pm 1,84$ & $57,22 \pm 4,56$ & $63,60 \pm 0,23$ & $59,60 \pm 9,99$ \\
Ureia & $34,40 \pm 2,30$ & $33,05 \pm 2,20$ & $18,58 \pm 5,62^{*}$ & $27,10 \pm 2,79$ \\
Creatinina & $0,70 \pm 0,04$ & $0,68 \pm 0,02$ & $0,60 \pm 0,09$ & $1,00 \pm 0,10^{*}$ \\
Albumina & $2,60 \pm 0,13$ & $2,25 \pm 0,13$ & $2,57 \pm 0,13$ & $3,30 \pm 0,08^{*}$ \\
Proteínas totais & $7,26 \pm 0,16$ & $6,94 \pm 0,15$ & $5,70 \pm 0,57^{*}$ & $7,10 \pm 0,30$ \\
Globulina & $4,66 \pm 0,25$ & $4,69 \pm 0,21$ & $3,12 \pm 0,70$ & $3,80 \pm 0,24$ \\
Bili. direta & $0,06 \pm 0,03$ & $0,16 \pm 0,05$ & $0,06 \pm 0,07$ & $0,20 \pm 0,09$ \\
Bili. indireta & $0,14 \pm 0,04$ & $0,39 \pm 0,05$ & $0,10 \pm 0,03$ & $0,90 \pm 0,15^{*}$ \\
Bili. Total & $0,20 \pm 0,04$ & $0,55 \pm 0,08$ & $0,16 \pm 0,07$ & $1,10 \pm 0,24^{*}$ \\
Sódio & $142,40 \pm 1,31$ & $136,60 \pm 1,99^{*}$ & $155,50 \pm 0,35^{*}$ & $146,00 \pm 0,67$ \\
Potássio & $4,28 \pm 0,06$ & $4,36 \pm 0,12$ & $5,25 \pm 0,04^{*}$ & $5,00 \pm 0,26$ \\
\hline
\end{tabular}

*Difere $(\mathrm{P}<0,05)$ do controle, ANOVA seguido de Dunnett

FA: fosfatase alcalina; AST: aspartato aminotransferase; ALT: alanina aminotransferase.

Nos pulmões dos animais tratados, foram observados congestão moderada e infiltrado de macrófagos, linfócitos e alguns plasmócitos e eosinófilos (Fig. 4-A). O infiltrado inflamatório encontrado nos intestinos era de origem linfoplasmocitário e histiocítico (Fig. 4-B). Os linfonodos mesentéricos apresentavam edema moderado a acentuado, presença de linfócitos atípicos, plasmócitos e macrófagos contendo hemossiderina, além de desorganização do tecido linfoide. No fígado, foi observada a presença de congestão, infiltrado periportal linfoplasmocitário e histiocítico, degeneração hepática vacuolar centrolobular e colestase discreta a moderada (Fig. 4-C). Nos rins, as alterações consistiram em congestão, dilatação da cápsula de Bowman com deposição de material proteináceo e degeneração dos túbulos renais (Fig. 4-D).

Resultados anteriores mostraram que caprinos e ovinos que receberam alimentação forçada com as sementes decorticadas (amêndoas) de $J$. curcas nas doses de 0,05 a $10 \mathrm{~g} / \mathrm{kg}$ apresentaram toxicidade aguda e mortalidade a partir do segundo dia de tratamento, na maior dose. Diarreia, desidratação e perda de condição corporal foram os sinais clínicos mais proeminentes, acompanhados de alterações bioquímicas e anátomohistopatológicas compatíveis com lesões hepatorrenais, alterações que se confirmaram no presente estudo. Contudo, nesses estudos anteriores, a intoxicação causada pelas amêndoas parece ter sido mais grave, pois, adicionalmente, os animais apresentaram ataxia, redução de glicose, hemorragias no rúmen, retículo, baço, rins e coração, gelatinização da pelve renal, abomasite catarral ou hemorrágica, anemia macrocítica e normocrômica e $100 \%$ de mortalidade (Adam e Magzoub, 1975; Ahmed e Adam, 1979; Abdel-Gadir et al., 2003).

As variáveis hematológicas neste estudo não foram alteradas, fato já observado por Abdel-Gadir et al. (2003). Segundo esses autores, apenas no caprino que recebeu a menor dose $(0,25 \mathrm{~g} / \mathrm{kg})$ de J. curcas, $1 \mathrm{~g} / \mathrm{kg}$, ocorreu eritrocitose. 

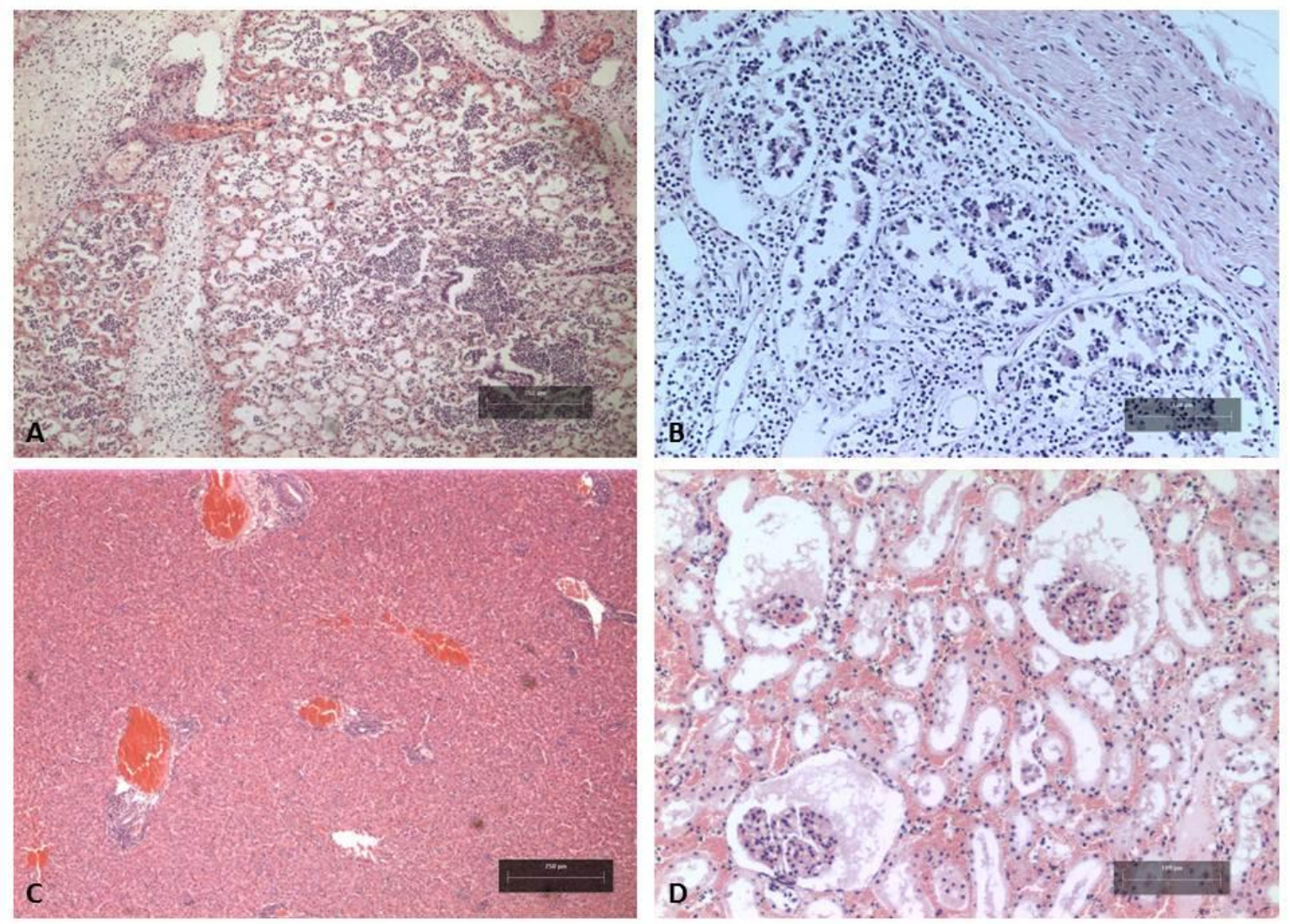

Figura 4. Fotomicrografia de cortes histológicos dos pulmões e intestino delgado de ovinos alimentado por 23 dias com a concentração de $30 \%$ do pericarpo de Jatropha curcas. A- pulmões, pneumonia linfo-

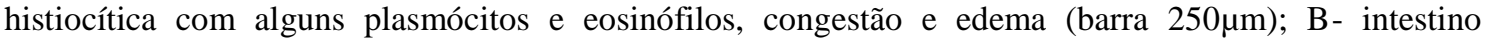

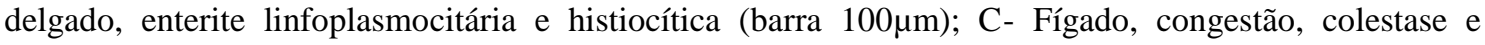

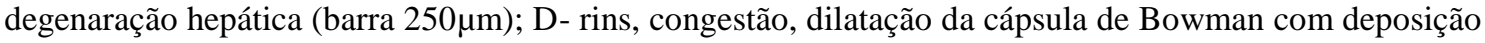
de material proteináceo e degeneração dos túbulos renais (barra $100 \mu \mathrm{m}$ ).

Tabela 2. Intensidade das lesões histopatológicas observadas em ovinos-controle e ovinos alimentados por 23 dias com dieta com diferentes porcentagens de pericarpo de J. curcas na dieta

\begin{tabular}{llcccc}
\hline \multirow{2}{*}{ Órgão } & \multirow{2}{*}{ Achado } & \multicolumn{3}{c}{ Intensidade das lesões } \\
\cline { 3 - 6 } & Edema & Controle & G15 & G30 & G45 \\
\cline { 2 - 6 } Pulmões & Congestão & - & ++ & ++ & ++ \\
& Infiltrado inflamatório linfo-histiocítico & - & ++ & ++ & ++ \\
& Degeneração centrolubar & - & ++ & ++ & ++ \\
\hline & Colestase & - & ++ & ++ & ++ \\
Fígado & Congestão & - & ++ & + & ++ \\
& Dilatação dos sinusoides & - & ++ & + & ++ \\
Rins & Degeneração tubular & - & + & ++ & + \\
\hline Abomaso & Congestão & - & + & ++ & + \\
\hline Intestinos & Infiltrado inflamatório linfo-histiocítico & - & ++ & + & ++ \\
\hline Linfonodos & Edema & - & ++ & + & ++ \\
mesentéricos & Infiltrado inflamatório histioplasmocitário & - & ++ & + & + \\
\hline
\end{tabular}




\section{Ferreira et al.}

As alterações nas concentrações de ureia, proteínas totais, AST, albumina, potássio e sódio foram consistentes com os achados de Ahmed e Adam (1979) e Abdel-Gadir et al. (2003), refletindo injúrias hepáticas $\mathrm{e}$ renais. A diminuição de fosfatase alcalina observada neste estudo pode estar relacionada à redução de consumo de alimento, pois reduções da enzima também foram encontradas em bovinos com restrição alimentar (Miller et al., 1969). O aumento de creatinina apenas no G45 também parece estar relacionado à redução do consumo de alimento, visto que ela é encontrada em quantidade $50 \%$ maior em caprinos alimentados com dietas que contêm baixa quantidade de proteína (Valtonen et al., 1982).

A elevação de bilirrubina verificada neste estudo é reflexo da citotoxicidade hepática, pois injúrias aos hepatócitos comprometem a conversão da bilirrubina não conjugada em bilirrubina conjugada, levando ao acúmulo desse pigmento no plasma, uma vez que a bilirrubina livre não é solúvel em água e, portanto, não é filtrada pelos glomérulos renais, não sendo excretada pela urina (Kaneko et al., 2008).

Segundo Li et al. (2010), a intensidade das alterações tóxicas observadas em ruminantes que consumiram as amêndoas da planta estaria diretamente relacionada às doses de ésteres de forbol consumidas. Assim, a ingestão de $0,05 \mathrm{~g} / \mathrm{kg}$ de semente de $J$. curcas corresponde à dose de $1,4-1,9 \mathrm{mg} / \mathrm{kg}$ de ésteres de forbol e produz morte entre 19 e 25 dias de tratamento. Já a ingestão de $10 \mathrm{~g} / \mathrm{kg}$ de semente da planta corresponde à dose de $30-45 \mathrm{mg} / \mathrm{kg}$ de ésteres de forbol e produz a morte entre dois e três dias.

No presente estudo, as doses de ésteres de forbol ingeridas pelos ovinos de G15, G30 e G45 no primeiro e no último dia do experimento foram de 0,5700 e $1,0588 \mathrm{mg} / \mathrm{kg} ; 1,0591 \mathrm{e}$ $1,3578 \mathrm{mg} / \mathrm{kg}$; e 0,8625 e $0,7965 \mathrm{mg} / \mathrm{kg}$, respectivamente. Tal informação justifica a baixa mortalidade observada neste estudo, quando comparada aos estudos anteriores em ruminantes, e demonstra que a toxicidade do pericarpo deve estar associada à presença dos ésteres de forbol, uma vez que os ésteres de forbol extraídos do óleo da $J$. curcas administrados a ratos promoveram toxicidade dose-dependente, com redução transitória do consumo de alimento e alterações histopatológicas semelhantes às encontradas neste estudo e nos estudos em ruminantes ( $\mathrm{Li}$ et al., 2010). Dessa forma, a hepatite tóxica e demais alterações verificadas neste estudo parecem ser resultado da ação direta dos ésteres de forbol ou de seus metabólitos tóxicos sobre os hepatócitos, uma vez que compostos dessa classe podem sofrer conversão metabólica pela ação de lipases (Mentlein, 1986).

Assim, este estudo demonstrou a toxicidade subcrônica do pericarpo de J. curcas para ovinos, caracterizada pela redução no consumo da dieta e ganho de peso, associada a alterações bioquímicas e anatomopatológicas que refletiram danos severos aos intestinos, pulmões, fígado e rins. Os efeitos tóxicos do pericarpo de J. curcas assemelham-se àqueles observados após a ingestão das sementes e podem ser atribuídos à presença de ésteres de forbol.

\section{CONCLUSÕES}

O pericarpo de $J$. curcas proveniente da produção de biodiesel na Amazônia Oriental contém ésteres de forbol e é tóxico para ovinos, provocando alterações caracterizadas por distúrbios digestivos, pulmonares, renais $\mathrm{e}$ hepáticos e, portanto, não é recomendado para a alimentação animal.

\section{AGRADECIMENTOS}

O presente trabalho foi realizado com o apoio do Conselho Nacional de Desenvolvimento Científico e Tecnológico-CNPq. Beneficiário de auxílio financeiro da CAPES - Brasil.

\section{REFERÊNCIAS}

ABDEL-GADIR, W.S.A.; ONSA, T.O.; ALI, W.E.M. et al. Comparative toxicity of Croton macrostachys, Jatropha curcas and Piper abyssinica seeds in Nubian goats. Small Rum. Res., v.48, p.61-67, 2003.

ADAM, S.E.I.; MAGZOUB, M. Toxicity of Jatropha curcas for goats. Toxicology, v.4, p.347-354, 1975

AHMED, O.M.M.; ADAM, S.E.I. Toxicity of Jatropha curcas in sheep and goats. Res. Vet., v.27, p.89-96, 1979.

BECKER, K.; MAKKAR, H.P.S. Jatropha curcas: a potential source tomorrow's oil and biodiesel. Lipid Technol., v.20, p.104-107, 2008. 
DEVAPPA, R.K.; MAKKAR, H.P.S.; BECKER, K. Jatropha Toxicity - a review. J. Toxicol. Environ. Health B., v.13, p.476-507, 2010.

GRAPHPAD PRISM. Graphpad software. Version 3.00. San Diego, 1999. Disponível em: <http://www.graphpad.com>. Acessado em: 12 fev. 2010.

GRINER, E.M.; KAZANIETZ, M.G. Protein kinase C and other diacylglycerol effectors in cancer. Nat. Rev. Cancer, v.7, p.281-294, 2007.

GOEL, G.; MAKKAR, H.P.S.; FRANCIS, G. et al. Phorbol Esters: Structure, Biological Activity and Toxicity in Animals. Int. J. Toxicol., v.26, p.279-288, 2007.

GOEL, G.; PUNIYA, A.K.; AGUILAR, C.N. et al. Interaction of gut microflora with tannins in feeds. Naturwissenschaften, v.92, p.497-503, 2005.

JAYANEGARAA, A.; PALUPI, E. Condensed tannin effects on nitrogen digestion in ruminants: A metaanalysis from in vitro and in vivo studies. J. Med. Pet., v.33, p.176-181, 2008.

KANEKO, J.J.; HARVEY, J.W.; BRUSS, M.L. Clinical Biochemistry of Domestic Animals. San Diego: Elsevier, 2008. 986p.

KING, A.J.; JESUS, A.C.; FREUDENBERG, M. et al. Potential of Jatropha curcas as a source of renewable oil and animal feed. J. Exp. Bot., v.2, p.1-9, 2009

KUMAR, A.; SHARMA, S. An evaluation of multipurpose oil seed crop for industrial uses (Jatropha curcas L.): A review. Ind. Crops Prod., v.28, p.1-10, 2008.

LI, C.Y.; DEVAPPA, R.K.; LIU, J.X. et al. Toxicity of Jatropha curcas phorbol esters in mice. Food Chem. Toxicol., v.48, p.620-625, 2010

MAKKAR, H.P.S.; ADERIBIGBE, A.O.; BECKER, K. Comparative evaluation of non-toxic and toxic varieties of Jatropha curcas for chemical composition, digestibility, protein degradability and toxic factors. Food Chem., v.62, p.207-215, 1998.

MAKKAR, H.P.S.; BECKER, K. Jatropha curcas, a promising crop for the generation of biodiesel and value-added coproducts. Eur. J. Lipid Sci. Technol., v.111, p.773-778, 2009.
MAKKAR, H.P.S.; BECKER, K; SPORER, F. et al. Studies on nutritive potential and toxic constituents of different provenances of Jatropha curcas. J. Agric. Food Chem., v.45, p.3152-3157, 1997.

MENTLEIN, R. The tumor promoter 12-Otetradecanoyl phorbol 13-acetate and regulatory diacylglycerol are substrates for the same carboxylesterase. J. Biol. Chem., v.261, p.7816-7818, 1986.

MILLER, W.J.; MARTIN, Y.G.; BLACKMON, D.M. et al. Effects of high protein diets with normal and low energy intake on wound healing, hair growth, hair and serum zinc and serum alkaline phosphatase in dairy heifers. J. Nutr., v.98, p.411-419, 1969.

PARAWIRA, W. Biodiesel production from Jatropha curcas: a review. Sci. Res. Ess., v.5, p.1796-1808, 2010.

PROVENZA, F.D.; PFISTER, J.A.; CHENEY, C.D. Mechanisms of learning in diet selection with reference to phytotoxicosis in herbivores. J. Range Manag., v.45, p.36-45, 1992.

RIBEIRO, J.A.A.; SCHWERZ JÚNIOR, P.; SOUSA, P.M. et al. Desenvolvimento de processo semiautomatizado para a extração e quantificação de éster de forbol em torta de pinhão-manso (Jatropha curcas L). In: CONGRESSO DA REDE BRASILEIRA DE TECNOLOGIA DE BIODIESEL, 4. 2010, Belo Horizonte. Anais... Belo Horizonte: Biodiesel: inovação tecnológica e qualidade, 2010. p.1241-1242. (Resumo).

SEN, S.; MAKKAR, H.P.S.; BECKER, K. Alfalfa saponins and their implication in animal nutrition. $J$. Agric. Food Chem., v.46, p.131-140, 1998.

VASCONCELOS, I.M.; OLIVEIRA, J.T.A. Antinutritional properties of plant lectins. Toxicon, v.44, p.385-403, 2004.

VALTONEN, M.H.; UUSI-RAUVA, A.; ERIKSSON, L. The effect of protein deprivation on the validity of creatinine and urea in evaluation of renal function. An experimental study in the goat. Scand. J. Clin. Lab. Invest., v.42, p.507-512, 1982. 